\title{
CAUSATION AND THE LAW: PREEMPTION, LAWFUL SUFFICIENCY, AND CAUSAL SUFFICIENCY
}

\author{
RICHARD FUMERTON* AND KEN KRESS**
}

\section{INTRODUCTION}

Richard Wright's attempt to distinguish actual causation from proximate causation, and to analyze actual causation-particularly in tort law-has been the most successful and influential work in this area in recent years. ${ }^{1}$ Indeed, most scholars think that Wright's analysis of cause as a necessary element in a set of conditions ("NESS") sufficient for an effect ${ }^{2}$ is an improvement upon H.L.A. Hart and Tony Honoré's classic discussion. ${ }^{3}$ In the decade and a half since Wright put forth his theory of causation, there have been a number of attempts to criticize him, but none has undermined the central thrust of his theory. ${ }^{4}$ While Wright's view has received deserved praise, his analysis of a NESS

Copyright (C) 2001 by Richard Fumerton and Ken Kress

This article is also available at http://www.law.duke.edu/journals/64LCPFumerton.

* Professor of Philosophy, University of Iowa.

** Professor of Law, University of Iowa.

We would like to thank Michael Moore and Heidi Moore for hosting a conference at the Institute for Legal Philosophy at the University of Pennsylvania School of Law at which we had the opportunity to discuss many of these issues. Many of the ideas put forth in this paper grew out of dialogue that involves too many participants in the conference to name individually. We are particularly grateful to Richard Wright, a participant in that conference, for his helpful remarks both at the conference and in subsequent discussion of drafts of this article. Needless to say, he disagrees with some of the conclusions we reach. Finally, we would like to thank the participants in a graduate seminar on Causation and the Law, Spring 1999, at the University of Iowa.

1. See Richard W. Wright, Actual Causation vs. Probabilistic Linkage: The Bane of Economic Analysis, 14 J. Legal STUd. 435 (1985); Richard W. Wright, Causation in Tort Law, 73 CAL. L. ReV. 1735 (1985) [hereinafter Wright, Causation]; Richard W. Wright, Causation, Responsibility, Risk, Probability, Naked Statistics, and Proof: Pruning the Bramble Bush by Clarifying the Concepts, 73 IowA L. REV. 1001 (1988) [hereinafter Wright, Bramble Bush]; see also Stephen R. Perry, The Impossibility of General Strict Liability, 1 CAN. J.L. \& JURIS. 147, 157 (1988) ("[T]he most sophisticated theoretical account of causation in tort law of which I am aware [is] the analysis recently advanced by Richard Wright.").

2. The NESS test is described infra in text accompanying notes 20-29.

3. See H.L.A. HART \& TONy HonOré, CAUSATION In THE LAw 109-14 (2d ed. 1985).

4. See, e.g., Mark Kelman, The Necessary Myth of Objective Causation Judgments in Liberal Political Theory, 63 CHI.-Kent L. REV. 579 (1987); Jane Stapleton, Legal Cause: Cause-in-Fact and the Scope of Liability for Consequences, 54 VAND. L. REV. (forthcoming 2001). David Fischer does make some telling remarks in the limited area of double omission cases. See David A. Fischer, Causation in Fact in Omission Cases, 1992 UTAH L. REV. 1335 (using example where auto repairman fails to fix brakes, and driver fails to hit the brakes). 
requires clarification. Once clarified, however, it is vulnerable to certain fundamental objections.

Wright's stated aim is to capture a nonnormative concept of causation. Therefore, this article begins by briefly describing the normative/nonnormative distinction, and how one might invoke this distinction to locate a nonnormative dimension of actual causation (as opposed to proximate causation). After briefly introducing Wright's concept of a NESS for an effect (the concept in terms of which he wants to understand actual causation), the article notes ambiguities in the critical concepts of necessity and sufficiency that he deploys. The article distinguishes a number of different modal concepts and suggests the most plausible interpretation of Wright's use of these concepts.

With a more precise understanding of Wright's view in hand, we turn to the question of whether his analysis more effectively handles difficult cases of causation-including multiple causes, preemption, omissions and the like-than does the nearly universal "but for" test deployed by courts as a test of actual causation. While Wright's test has certain advantages over the "but for" test, the article argues that it faces difficult problems of its own. First, it is not clear that Wright can accommodate indeterministic causation. Nor, contrary to what he claims, can his account adequately explain all cases of overdetermination involving preemption. The most obvious revision of Wright's theory to handle cases of preemption (replacing a concept of lawful sufficiency with one of causal sufficiency - a revision with which Wright has indicated sympathy) risks vicious conceptual circularity. It hardly seems likely that one will gain insight into the nature of causation through an account that relies on an understanding of that special kind of sufficiency involved in causation.

\section{II}

\section{CAUSATION AND NORMATIVITY}

Legal theorists have tried to distinguish nonnormative issues from those that include a normative element. ${ }^{5}$ Obvious candidates for nonnormative issues are questions concerning causation. For example, if you are suing me for damages in tort, one of the things you must establish for your suit to be successful is that some action I took caused the relevant damages. ${ }^{6}$ This part of your burden seems straightforwardly factual in a way in which, say, your burden of showing that I acted negligently (or tortiously) may not be. It seems plausible on its face

5. See Wright, Causation, supra note 1, at 1741-58. Legal positivism is the doctrine that law and morals are not conceptually linked, and that law is a matter of facts and social conventions. See generally H.L.A. HART, THE CONCEPT OF LAW (2d ed. 1994); JOSEPH RAZ, THE CONCEPT OF A LEGAL SYSTEM (2d ed. 1994); Jules Coleman, Negative and Positive Positivism, 11 J. LEG. STUD. 139 (1982). Natural law is the doctrine that there is a conceptual or essential connection between law and morality. See generally JOHN FINNIS, NATURAL LAW AND NATURAL RIGHTS (1980); NATURAL LAW THEORY: CONTEMPORARY ESSAYS (Robert P. George ed., 1992).

6. If I had a duty to act, yet failed to act, then you must prove that my omission caused the injury. This latter case already embodies a nonnormative element—causation—and a normative componentduty. 
to suppose that negligence is a normative notion. When people act negligently, they do not exercise due care. They do not take precautions they ought to take in the face of various possible harms. The italicized terms are paradigm value terms that indicate our subject has taken a normative turn.

Before proceeding, it might be worth elaborating on this distinction between nonnormative and normative questions. Some people describe nonnormative issues as factual and normative issues as nonfactual. Many ethical philosophers resist this way of presenting the contrast. These philosophers argue that normative, ethical judgments are factual judgments. Some of these descriptivists are subjectivists, but others would claim that ethical statements make objective assertions. ${ }^{7}$ There are moral truths, the objectivists would argue. Moreover, objectivists would urge that whether some things are good (or actions are right, prohibited, permitted, or required) is a truth that is objective in the sense that it does not depend in any way on people's beliefs about or attitudes toward that which exemplifies the moral property. If moral judgments are a paradigm of normative judgments, then such philosophers will reject the suggestion that we should contrast the normative with the factual. They might still allow that there is a normative/nonnormative distinction-that there is a contrast, in Hume's terms, between "is" statements and "ought" statements ${ }^{8}$ - but it is difficult to determine what the contrast is, and how to articulate it-particularly for objectivists and cognitivists. ${ }^{9}$ For the purpose of the current discussion, it will suffice simply to stipulate that a normative claim is one that can be expressed by "good"/"bad," "right"/"wrong," "ought"/"ought not," or any other term that can be defined in part by these..$^{10}$ Those who are uneasy about the possibility of reducing all other ethical concepts to those on our relatively short list may supplement this list of paradigm normative expressions.

7. See, e.g., G.E. MoORE, PrinCIPIA ETHICA (1903). Moore clearly rejects the suggestion that ethical (normative) questions should be contrasted with factual questions. The point applies more generally to any cognitivist in ethics. See also PANAYOT BUTCHVAROV, SKEPTICISM IN ETHICS (1989) (objectivist); Richard FumERTON, REASON AND MORALITY: A DEFENSE OF THE EgOCENTRIC PERSPECTIVE (1990) (subjectivist); ALAN GEWIRTH, REASON AND MORALITY (1978) (objectivist).

8. See David Hume, A Treatise of Human Nature 469 (L.A. Selby-Bigge ed., Clarendon Press 1978) (1888).

9. Cognitivists claim that ethical statements have truth values. Noncognitivists might have an easier time distinguishing the normative from the nonnormative. Prescriptivists, for example, argue that ethical judgments are "disguised" imperatives, and they are therefore in a position to contrast the factual (the descriptive) with the normative (the prescriptive). See, e.g., R.M. HARE, FrEEDOM AND REASON (1952) (a classic discussion of prescriptivism). The earlier, more primitive forms of emotivism (views according to which ethical statements express, but do not describe, attitudes) also sharply distinguished the factual from the normative. See, e.g., C.L. Stevenson, The Emotive Meaning of Ethical Terms, 46 MIND 14 (1937).

10. Although this definition suffices for our purposes, a full attempt to distinguish the normative from the nonnormative would require a more nuanced discussion of different uses of terms like "good" and "ought." For example, some would urge that "good arguments," "good toasters," and "good assassins" are nonnormative locutions. Others would claim that prudential statements, such as "you ought to avoid eating too much fat," are not normative. For a fuller discussion of these issues, see Richard Fumerton, Epistemic Justification and Normativity, in KNOWLEDGE, TRUTH, AND DUTY: ESSAYS ON EPISTEMIC RESPONSIBILITY AND THE ETHICS OF BELIEF 49 (Mathias Steup ed., 2001). 
A. Normative Decisions Concerning the Introduction of Nonnormative Considerations

Even if we are clear about the distinction between factual and normative issues, another distinction must be made to avoid potential confusion. It may be that determinations of law involve nonnormative matters of fact, but our decision to make a given nonnormative fact relevant to a finding of law is itself grounded in normative considerations. We should distinguish between two levels here. In the first level, we operate as lawyers, and deploy a notion of actual causation that is nonnormatively factual or empirically based. At a second, or meta-level, we justify our deployment of a factual, nonnormative concept of actual causation at the first level, the level of the actual practice of lawyers and courts. This meta-level justification may be fully normative.

This is a perfectly coherent strategy, consistent with one perspective on what legal positivist methodology has been at least since Jeremy Bentham. ${ }^{11}$ For example, a theorist who believes that the morality and justice of case outcomes are the most important normative considerations might argue that distinguishing causation into a nonnormative actual cause component, and a normative, proximate cause component will lead to clarity resulting in morally better and more just decisions. A moral philosopher might urge that having a nonnormative, actual cause requirement better manifests the ultimate nature of justification in tort law as corrective justice than any alternative. A law and economics scholar might urge that having a nonnormative actual cause requirement leads to more efficient decisions. For our concerns, it does not matter which justification is better. Rather, what is relevant here is that each theorist provides a moral, normative reason why the actual cause requirement should be nonnormative.

On the face of it, questions of actual causation are not normative questions. That I caused your death by stabbing you through the heart with a knife is hardly a matter that involves reflection on normative issues, that is, on questions of good and bad, right and wrong, what people should or should not do. Matters become more complicated, however, once we reflect on the fact that disputes arise over causation that do not seem to have much to do with empirical matters. You were carelessly driving down a street while I was crossing

11. See, e.g., W.L. Morison, John Austin (1982); Gerald J. Postema, Bentham And the COMMON LAW TRADiTiOn 147-90, 328-36 (1986). Even in the famous Hart/Fuller debate, Fuller accused Hart of giving both descriptive and normative reasons for legal positivism. See Lon L. Fuller, Positivism and Fidelity to Law-A Reply to Professor Hart, 71 HARV. L. REV. 630, 630-31 (1958). The most sophisticated proponent of the view that there can be normative reasons for the law to be nonnormative and descriptive is Stephen Perry. See Stephen R. Perry, Hart's Methodological Positivism, 4 LEGAL THEORY 427 (1998); Stephen R. Perry, Holmes versus Hart: The Bad Man in Legal Theory, in The PATH OF THE LAW AND ITS INFLUENCE: The LEGACY OF Oliver Wendell Holmes, JR. 158 (Steven J. Burton ed., 2000); Stephen R. Perry, Interpretation and Methodology in Legal Theory, in LAW AND INTERPRETATION: ESSAYS IN LEGAL PHILOSOPHY 97 (Andrei Marmor ed., 1995). We might think, for example, that analytic clarity and justice are both enhanced by distinguishing causation into two concepts: actual causation (an empirical, factual notion), and proximate causation (a normative concept). This position is analogous to H.L.A. Hart's argument in favor of legal positivism in his debate with Lon Fuller. See Fuller, supra. 
against a red light. You carelessly leave a log in the middle of the street, and I negligently drive in excess of the speed limit, which prevents me from stopping in time. Who was causally responsible for my injuries? Did I cause my own injuries through my negligent behavior or did you cause my injuries through your negligent behavior? Is it not plausible to suppose that our choice to describe one or the other of these acts as "the cause" is guided by our pretheoretical intuitions about who is responsible? Furthermore, this notion of responsibility goes beyond matters of empirical fact, and reintroduces normative concepts. ${ }^{12}$

\section{B. Causes, Proximate Causes, and Causally Relevant Factors-Attempting to Isolate the Nonnormative}

The law recognizes the need to distinguish morally and legally relevant causal factors from irrelevant causal factors. The concept of tortious conduct serves to narrow the class of all causal factors to the tortious causal factors. The concept of proximate cause narrows the class of all tortious causal factors to the legally responsible tortious factors. ${ }^{13}$ As a result, the notion of proximate cause plays a prominent role in judicial decisions and instructions promulgated to juries. A proximate cause is typically defined as a cause that produces injury in a natural, direct, and continuous sequence without any superseding causes that break the causal chain. ${ }^{14}$ Alternatively, a proximate cause is defined as a tortious cause that results in a reasonably foreseeable injury to a reasonably foreseeable plaintiff. ${ }^{15}$ Sometimes the relationship between an action by the defendant and the injury to the plaintiff is simply too attenuated to sustain a judgment of legal responsibility and damages. For example, suppose a defendant recklessly endangers nearby persons and property by throwing a stone,

12. See KeEton Et Al., Prosser AND KeEton ON TORTS 280 (5th ed. 1984) [hereinafter PROSSER \& KEETON]; Wright, Bramble Bush, supra note 1, at 1012-14; Wright, Causation, supra note 1 , at $1741-50$. 50.

13. See Wright, Bramble Bush, supra note 1, at 1004-14; Wright, Causation, supra note 1, at 1737-

14. See Glasgow Realty Co. v. Metcalfe, 482 S.W.2d 750 (Ky. 1972) (holding that third parties' negligent behavior in applying force to window that fell, injuring plaintiff, did not constitute a superseding or intervening cause relieving defendant apartment owner of liability for negligent maintenance because behavior of third party was foreseeable); Gilbert v. New Mexico Const. Co., 44 P.2d 489 (N.M. 1935) (holding that city's failure to maintain reasonable water pressure after repairing damage to the water system negligently caused by defendant was not a superseding cause relieving defendant of liability for damages due to fire that would have been mitigated had water pressure been at normal pressures). See generally GeORGE C. Christie ET Al., CASES AND MATERIALS ON THE LAW OF TORTS, 326-36 (3d ed. 1997); RESTATEMENT (SECOND) OF TORTS §§ 440-53 (1965); COMMITTEE ON STANDARD JURY INSTRUCTIONS, CALIFORNIA JURY INSTRUCTIONS, BOOK OF APPROVED JURY INSTRUCTIONS (BAJI) § 3.79 (8th ed. 1995) (When Third Party's Intervening Negligence is Not a Superseding Cause).

15. See Overseas Tankship (U.K) Ltd. v. Morts Dock \& Eng'g Co. (The Wagon Mound) [1961] App. Cas. 338 (P.C. 1961); Palsgraf v. Long Island R.R., 162 N.E. 99 (N.Y. 1928). A third, but ultimately unhelpful, jury instruction - the substantial factor test-is given in some jurisdictions as a test of proximate causation, not only actual causation, in cases of multiple causation. See, e.g., Jones v. City of Des Moines, 355 N.W.2d 49, 50 (Iowa 1984) (and the cases cited therein); Iowa Civil Jury Instruction 700.3-Proximate Cause Defined; REstATEMENT (SECOND) OF TORTs $§ 431$ (1965). 
which hits a bird, causing the bird to lose consciousness, and fall into a smokestack. The bird catches fire, regains consciousness, flies out, and expires over a nearby fireworks factory. It falls into the main storeroom-still flaming-and ignites several cases of fireworks, which explode. The vibrations from the explosion cause a flowerpot to fall off a windowsill ten blocks away and land on the plaintiff's head, causing injury. Under the foreseeability test-and perhaps the superseding cause test-for proximate causation, the defendant would be excused from liability even though the defendant's reckless behavior was an actual cause of the plaintiff's injury, because it was not foreseeable that throwing the stone would result in the flowerpot hitting the plaintiff on the head. ${ }^{16}$

The work accomplished by this notion of proximate causation is therefore normative work. It distinguishes defendants who are obliged to pay damages from those who are not, because only individuals who are proximate causes are liable for damages. Arguably, it distinguishes between individuals who are morally blameworthy and individuals who are not morally blameworthy, at least if tort liability requires moral blameworthiness in some objective sense. ${ }^{17}$

If this concept of proximate cause is normative, it does not follow that efforts to carve out a nonnormative component of legal responsibility are doomed. The previous discussion relied implicitly on the concept of a causally relevant factor: an actual cause. Which of the indefinitely many causally relevant factors constitute proximate causes or the causes with which we are concerned in a legal context may well involve normative elements that cannot be eliminated. Traditionally, it is said that the proximate cause concept selects from among all actual causes the legally responsible causes by invoking policy considerations. $^{18}$ But whether something is $a$ causally relevant factor in producing some outcome may be nonnormative through and through. One should not succumb to the temptation to suppose that relevant questions of causation are permeated by the normative even if the decision to focus only on certain causal factors is. This is essentially the point that Richard Wright tries to make in Causation, Responsibility, Risk, Probability, Naked Statistics, and Proof: Pruning the Bramble Bush by Clarifying the Concepts and Causation in Tort

16. Compare Judge Andrews's example of the chauffeur, who is not liable to C sitting a block away from the accident, in Palsgraf, 162 N.E. at 104 (Andrews, J., dissenting).

17. Tort liability does not require moral liability in a subjective sense. This is obvious in the case of strict liability, particularly strict liability for manufacturing defects. See RESTATEMENT (THIRD) OF TORTS $§ 2$ (1998) (providing a negligence analysis of design defect and failure to warn, and a strict liability analysis of manufacturing defects). However, even negligence liability does not require subjective fault, because breach deploys the reasonable person standard rather than subjective fault. See Vaughan v. Menlove, 132 Eng. Rep. 490 (1837) (defendant, a mentally challenged landowner, piled hay creating a fire hazard to neighbors held liable for damages from ensuing fire even though he was not subjectively at fault given his disability).

18. See, e.g., Palsgraf, 162 N.E. at 103 (Andrews, J., dissenting); William L. Prosser, LAW OF TORTS 244 (4th ed. 1971); PROSSER \& KEETON, supra note 12, at 272-73; Wright, Causation, supra note 1, at 1742 (noting that the question "Is there an applicable policy or principle which absolves the defendant from liability, even though his tortious conduct was a cause of the injury?" is the proximate cause inquiry). 
$L a w .{ }^{19}$ One of Wright's primary concerns is to identify a necessary condition for $\mathrm{X}$ causing $\mathrm{Y}$ that is unproblematically factual and nonnormative. The goal is to find an illuminating condition that will help to decide difficult causal legal issues. In the next section, we describe Wright's theory of actual causation and try to clarify key elements of the view.

III

\section{WRIGHT AND THE CONCEPT OF A NESS}

\section{A. Five Senses of Necessity and Sufficiency}

In this section, we discuss and make more precise the concept of a causally relevant factor that Wright tries to define in terms of a necessary element of an actual set of conditions that are sufficient for the effect ("NESS"). ${ }^{20}$ We find the general idea of the NESS test initially quite attractive. A version of the concept fares better than the older concept of the causally relevant factor defined by the "but for" test in some contexts. The concept of a NESS does not, however, do some of the work Wright claims it does. In particular, it presupposes a causally deterministic universe, and it does not handle cases of preemption in the way that Wright suggests. ${ }^{21}$ The article closes with some more general conclusions one might draw from the difficulties faced by the NESS test about the theoretical task of analyzing causation.

The traditional "but for" test of actual causation is deployed in most jurisdictions. It claims that a defendant is an actual cause of the plaintiff's injuries if and only if, had the defendant not acted tortiously (or negligently), the plaintiff would not have been injured. ${ }^{22}$ By contrast, Wright argues that for some action (or inaction) of an agent to be a cause of some state of affairs Y, that action must be a NESS, a necessary element of a set of actual antecedent conditions that is sufficient for the occurrence of $\mathrm{Y} .{ }^{23}$ That an action (or inaction) $\mathrm{X}$ is or is not a NESS for some $\mathrm{Y}$ is a purely factual matter untainted by normative considerations. ${ }^{24}$ As Wright acknowledges, his concept of a NESS is closely related to the earlier concept of an INUS condition introduced by J. L. Mackie in his

19. See Wright, Bramble Bush, supra note 1; Wright, Causation, supra note 1, at 1735.

20. See Wright, Causation, supra note 1, at 1774, 1790.

21. See id. at 1794-98.

22. See, e.g., Powers v. Standard Oil Co., 119 A. 273 (N.J. 1923); Boronkay v. Robinson \& Carpenter, 160 N.E. 400 (N.Y. 1928); Laidlaw v. Sage, 52 N.E. 679 (N.Y. 1899); Ham v. Greensboro Ice \& Fuel Co., 169 S.E. 180 (N.C. 1933); Schoonmaker v. Kaltenbach, 294 N.W. 794 (Wisc. 1940); TOM L. BeAuchamp \& Alex Rosenberg, Hume and THE Problem of CAUSATION 94-96, 98, 107-17, 119, 131-37, 139-45, 297 (1981); HART \& HONORÉ, supra note 3, at 15-16, 69, 110; WILliam PROSSER, HANDBOOK OF THE LAW OF TORTS $§ 41,237-39$ (4th ed. 1971); PROSSER \& KEETON, supra note 12, at 265-67; RESTATEMENT (SECOND) OF TORTS § 432(1) (1965); J.L. Mackie, Causes and Conditions, in CAusation AND CONDITIONAls 1, 16-21, 25-27 (Ernest Sosa ed., 1975); Glanville Williams, Causation in the Law, 1961 CAMBRIDGE L.J. 62, 63-64.

23. See Wright, Causation, supra note 1, at 1774, 1790.

24. See id. at 1743 . 
attempt to offer a partial analysis of causation. ${ }^{25}$ Mackie argued that a necessary condition for $\mathrm{X}$ having caused $\mathrm{Y}$ is that $\mathrm{X}$ is an insufficient but necessary part of an unnecessary but sufficient ("INUS") condition for the occurrence of Y. ${ }^{26}$ Wright does not rule out the possibility that the sufficient condition is also necessary and does not-as Mackie does-rule out the possibility that something $\mathrm{X}$ can be a cause of $\mathrm{Y}$ in cases of overdetermination. ${ }^{27} \mathrm{Y}$ is overdetermined in the legal sense when it has two causes, each of which would be sufficient by itself for $\mathrm{Y}^{28}$

An illustration of a NESS can be found in the anecdote in which Babe Ruth promised to hit a home run for a hospitalized young boy. In what was likely to be his last at-bat of the game, Ruth pointed into the stands and, after a few bad swings, connected. In typical Ruth style, it was a powerful home run. As soon as Ruth's bat connected, then, given other conditions-such as the lack of a brisk counter wind, or a tornado, or the fact that no lightning was going to strike the ball-given the weight of the ball and the resistance of air, it followed that the power with which Ruth hit the ball was a NESS of its being a home run. As another example, John's stabbing of Mary in the heart caused her death because it was a necessary element in a set of actual conditions-including her being alive at the time that she was stabbed and the stabbing hitting her heart in a crucial central location, and there having been no hospital nearby where she could receive a blood transfusion or heart surgery - that together are sufficient in light of physiological and physical laws to entail that Mary would die.

While the concept of a NESS seems intuitively clear, it is important to analyze the critical concepts of necessity and sufficiency employed in the NESS test more precisely than Wright does. There are many different senses in which we may speak of one condition being necessary or sufficient for another, and we must be clear about how we are understanding the use of these terms in the definition of a NESS. We should distinguish all of the following:

(1) $\mathrm{X}$ is a formally necessary/sufficient condition for $\mathrm{Y}$ (knowable $a$ priori).

25. See J.L. Mackie, Causes and Conditions, in CAUSATION 33 (Ernest Sosa \& Michael Tooley eds., 1993); Wright, Bramble Bush, supra note 1, at 1023-34; Conversation between the authors and Richard W. Wright, Iowa City, Iowa (Nov. 4, 2000). Wright's notion of a NESS also borrowed heavily from Hart \& Honoré's earlier discussion. See HART \& HONORÉ, supra note 3.

26. See Mackie, supra note 25, at 34-37.

27. See id. at 33, 36-39; see also Wright, Causation, supra note 1, at 1791.

28. See, e.g., Basko v. Sterling Drug, Inc., 416 F.2d 417 (2d Cir. 1969); Navigazione Libera v. Newton Creek Towing, Inc., 98 F.2d 694 (2d Cir. 1938); Anderson v. Minneapolis, St. P. \& S.S.M. Ry. Co., 179 N.W. 45 (Minn. 1920); Kingston v. Chicago \& N.W.R. Co., 211 N.W. 913 (Wisc. 1927); Cook v. Minneapolis, St. P. \& S.S.M. Ry. Co., 74 N.W. 561 (Wisc. 1898); Burmah Oil v. Lord Advocate, [1965] App. Cas. 75 (destruction of oil installations which would later have fallen into Japanese hands); R. v. Mgxwiti, 1954 (1) SA 370, 381; HART \& HONORÉ, supra note 3, at 122-25, 235-53; RESTATEMENT (SECOND) OF TORTS § 432(2) (1965); Mackie, supra note 25, at 42-45; Robert J. Peaslee, Multiple Causation and Damage, 47 HARV. L. REV. 1127 (1934); Michael Scriven, Defects of the Necessary Condition Analysis of Causation, in CAUSATION, supra note 25, at 56, 57-59; Wright, Bramble Bush, supra note 1, at 1022-24; Wright, Causation, supra note 1, at 1774-1812. Wright would also count cases in which five persons each put one drop of poison in the victim's coffee, and three drops are necessary to cause death, as in cases of overdetermination. 
(2) $\mathrm{X}$ is an analytically necessary/sufficient condition for Y (knowable $a$ priori).

(3) $\mathrm{X}$ is a synthetically necessary/sufficient condition for Y (knowable $a$ priori).

(4) $\mathrm{X}$ is a lawfully necessary/sufficient condition for Y (probably knowable only a posteriori).

(5) $\mathrm{X}$ is a causally necessary/sufficient condition for $\mathrm{Y}$ (probably knowable only a posteriori).

We shall consider each in turn:

\section{Formal Necessity and Sufficiency}

Let us say that $\mathrm{X}$ is a formally necessary condition for $\mathrm{Y}$ when the conjunction- $\mathrm{Y}$ but not $\mathrm{X}$-is a formal contradiction (put another way, "if $\mathrm{Y}$ then $\mathrm{X}$ " is a formal tautology). ${ }^{29}$ Let us say that $\mathrm{X}$ is a formally sufficient condition for $\mathrm{Y}$ when the conjunction $\mathrm{X}$ but not $\mathrm{Y}$ is a formal contradiction (or, in other words, when the conditional, if $\mathrm{X}$ then $\mathrm{Y}$, is a formal tautology). That the book is yellow is a formally necessary condition for the book's being yellow and rectangular. That the book is yellow and rectangular is a formally sufficient condition for the book's being yellow. A formal contradiction wears its falsehood on its sleeve, so to speak. One can determine solely by looking at the form of a proposition whether it is a formal contradiction. Notice that, in this sense, necessary and sufficient conditions are best conceived as expressed by propositions (bearers of truth value). A contradiction is a proposition that is necessarily false. Yet we may be able to speak in a derivative sense of facts being formally necessary or sufficient conditions for other facts. On one conception of truth, every true proposition is made true by some fact, a fact that, in some sense, shares the same form or structure as the proposition that expresses it. One might then be able to say that the fact that $\mathrm{X}$ was sufficient for the fact that $\mathrm{Y}$ when the proposition representing $X$ formally entails the proposition representing Y. While it may seem that this is a relatively esoteric metaphysical point, the issue is crucial, as we shall see ${ }^{30}$ to make sense of an action-as opposed to a truth about an action-constituting a NESS for some relevant effect.

\section{Analytic Necessity and Sufficiency}

Let us say that $\mathrm{X}$ is an analytically necessary condition for $\mathrm{Y}$ when the conjunction $\mathrm{Y}$ but not $\mathrm{X}$ is analytically false (when the conditional if $\mathrm{Y}$ then $\mathrm{X}$ is analytically true). $\mathrm{X}$ is an analytically sufficient condition for $\mathrm{Y}$ when the conjunction $\mathrm{X}$ but not $\mathrm{Y}$ is analytically false (when the conditional, if $\mathrm{X}$ then $\mathrm{Y}$, is analytically true). There is much disagreement on how to define analytic truths

29. A formal tautology, as distinct from an analytic tautology, is one whose truth is determined by the syntactic characteristics of certain terms. This characterization oversimplifies a bit because the meanings of connectives and certain conventions concerning the irrelevance of position in sentences to meaning are relevant to what makes tautologies true.

30. See infra text accompanying notes $40-41$. 
and falsehoods, ${ }^{31}$ but for our purposes, we will say that a proposition is analytically true if it can be turned into a formal tautology through the substitution of synonymous expressions, that is, expressions identical in meaning. Thus, to take a well-worn example, the proposition that bachelors are unmarried is analytically true. Unlike a formal tautology-or a formal contradiction-one can not discover its truth-or falsehood-solely by examining its form. One must reflect on the meaning of its constituent terms. But such reflection will reveal that part of what it means to describe someone as a bachelor is to say that he is unmarried. When we replace the term "bachelor" with its synonym "unmarried man" in the sentence, "Bachelors are unmarried," we get the formal tautology, "Men who are unmarried are unmarried." Being unmarried is an analytically necessary condition for being a bachelor; being a bachelor is an analytically sufficient condition for being unmarried. As with logical necessity and sufficiency, we may be able to speak in a derivative sense of facts being analytically necessary or sufficient for other facts.

\section{A Priori Synthetic Necessity and Sufficiency}

Some philosophers will also recognize the existence of synthetic necessity and sufficiency. ${ }^{32}$ The concepts are highly controversial and can probably best be explained negatively. $\mathrm{X}$ is a synthetically necessary condition for $\mathrm{Y}$ when it is impossible in some very strong sense for $Y$ to occur without $X$. It is a synthetically necessary truth, knowable a priori, that "if Y, then X," even though the proposition "if $Y$, then $X$ " is neither formally nor analytically true. $\mathrm{X}$ is synthetically sufficient for $\mathrm{Y}$ when it is a necessary truth in the above sense that if $\mathrm{X}$, then Y. For example, a triangle's having three equal sides might be a good example of a synthetically necessary condition for a triangle's having equal angles. It is necessarily true that if a triangle has equal angles, it has equal sides. But it is not a formal tautology (we cannot discover its truth by examining its form), and it does not look much like an analytic truth, because it is implausible to claim that "having equal sides" and "having equal angles" have the same meaning. We cannot transform the conditional, "If $\mathrm{X}$ is a triangle with equal angles, then X has equal sides," into a formal tautology through the substitution of synonymous expressions.

\section{Lawful Necessity and Sufficiency}

When we say that oxygen is necessary for fire, we are (arguably) not saying that oxygen is a formally necessary, an analytically necessary, or a synthetically (a priori) necessary condition for combustion. Unlike the relationship between

31. In his classic article Two Dogmas of Empiricism, Quine surveys and criticizes a number of different attempts to define analyticity. See W.V.O. Quine, Two Dogmas of Empiricism, in From A LOGICAL POINT OF VIEW 20 (2d ed. 1961); cf. Hilary Putnam, The Analytic and the Synthetic, in 2 Mind, LANGuage AND Reality: Philosophical PAPERS 33 (1975); P.F. Strawson \& H.P. Grice, In Defense of a Dogma, 65 PHIL. REV. 141 (1956).

32. See Immanuel Kant, Critique of Pure ReAson 48-58 (Norman Kemp Smith ed., Modern Library 1965) (1781). 
a triangle's having equal sides and its having equal angles, it does not seem that one could discover the dependence of fire on oxygen a priori. There is no formal contradiction in the claim that a fire occurred without the presence of oxygen, nor does it seem that one could discover the falsehood of that claim solely by reflecting on the meanings of the terms contained in the statement. One could only discover the impossibility of fire without oxygen through empirical investigation. In the first place, we might say that $\mathrm{X}$ is lawfully sufficient for $\mathrm{Y}$, if there are some laws of nature $\mathrm{L}$ such that (X and $\mathrm{L}$ ) is logically or analytically sufficient for Y (where neither X nor L alone is logically or analytically sufficient for Y). Assuming that it is a law of nature that fire takes place only in the presence of oxygen, then it will be true that both the presence of oxygen is a lawfully necessary condition for the occurrence of fire and that the occurrence of fire is a lawfully sufficient condition for the presence of oxygen. The definition presupposes an understanding of natural law, a concept that has resisted philosophical analysis for millennia. If we introduce the concept of lawful sufficiency into an analysis of causation-as Wright does-we will have taken a highly controversial philosophical position. Specifically, we will have endorsed what might be called a generality theory of causation. A generality theory of causation claims that an understanding of causation depends on an understanding of natural law. Note that the concept of lawful necessity and sufficiency seems most at home at the level of propositions-entities that are either true or false. If we are to use the concept the way we have defined it to characterize events or facts as lawfully necessary or sufficient conditions for other events or facts, we will again need to introduce a derivative sense in which the facts that make true propositions that stand in the relevant relations can themselves be said to stand derivatively in the relations.

\section{Causal Necessity and Sufficiency}

Given the way in which we define lawfully necessary and sufficient conditions, they do not equate straightforwardly with causally necessary and sufficient conditions. While it seems plausible on its face to suppose that causation involves temporal direction-causes must precede, or at the very least be contemporaneous with, their effects-lawful necessity and sufficiency do not. X can postdate $\mathrm{Y}$ and still be either lawfully necessary or sufficient for Y. To capture the distinction between causal necessity and sufficiency and lawful necessity and sufficiency, we may in the end need to introduce a species of natural law that we call "causal law" or "law of causal succession." It might be a law that, under certain circumstances, the rapid fall of a barometer will be followed by a storm, but that law does not describe a causal succession of events. The fall of a barometer in those conditions was neither a causally necessary nor a causally sufficient condition for the ensuing storm. If the sun is casting a fivefoot-long shadow on the ground when it is at a forty-five degree angle to a flag pole, we can infer from laws of nature that the flag pole is ten feet high. It does not follow that the shadow is causing the flag pole to be ten feet high. 


\section{B. The Senses of Necessity and Sufficiency Deployed in Wright's NESS Test}

Let us return to Wright's analysis. First, recall that Wright seems to be offering the definition of a NESS as a way to introduce a necessary condition for $\mathrm{X}$ being the cause of $\mathrm{Y}^{33}$ It seems obvious, given the above distinctions, that with the concept of a NESS, we are trying to identify an analytically necessary condition for one thing being a cause of another. Wright is implicitly claiming that it is an analytic truth that if X caused Y, then X is a NESS of $\mathrm{Y}^{34} \mathrm{He}$ is not claiming that $\mathrm{X}$ being a NESS of $\mathrm{Y}$ is an analytically sufficient condition for $\mathrm{X}$ being the cause of $\mathrm{Y}$ or, ipso facto, for $\mathrm{X}$ being a proximate cause of $\mathrm{Y}$, but he is probably claiming that $\mathrm{X}$ being a NESS of $\mathrm{Y}$ is an analytically sufficient condition for $\mathrm{X}$ being a causally relevant factor in the occurrence of $\mathrm{Y}^{35}$

$\mathrm{X}$ is a NESS of $\mathrm{Y}$ when $\mathrm{X}$ is a necessary element of some set of conditions that is sufficient for Y. Put another way, $\mathrm{X}$ is a NESS of $\mathrm{Y}$ when there exists some set of conditions $\mathrm{N}$ such that $\mathrm{X}$ is (in some sense) necessary for $\mathrm{N}$, and $\mathrm{N}$ is (in some sense) sufficient for $\mathrm{Y}$, where $\mathrm{N}$ minus $\mathrm{X}$ would not be sufficient for $\mathrm{Y}$. We need this last qualification to restrict NESSs to nonredundant parts of lawfully sufficient conditions for $\mathrm{Y}$. If $\mathrm{N}$ is lawfully sufficient for $\mathrm{Y}$, then so is $\mathrm{N}+$ $\mathrm{C}$ where $\mathrm{C}$ can be anything at all. If $\mathrm{N}$ by itself is lawfully sufficient for $\mathrm{Y}$, then $\mathrm{C}$ will trivially be a NESS of $\mathrm{Y}$ by being a logically necessary condition for the occurrence of $\mathrm{N}+\mathrm{C}-$ a state of affairs that is, by hypothesis, lawfully sufficient for Y.

It seems to us most plausible to suppose that the concept of necessity on which Wright's definition relies is logical or analytic necessity; the sense of sufficiency on which his definition relies is lawful sufficiency. ${ }^{36}$ In short, $\mathrm{X}$ is a NESS for $\mathrm{Y}$ when there is some state of affairs $\mathrm{N}$ of which $\mathrm{X}$ is a logical constituent, and where $\mathrm{N}$ is a lawfully sufficient condition for $\mathrm{Y}$, yet the state of affairs $(\mathrm{N}$ $\mathrm{X}$ ) that would result from subtracting $\mathrm{X}$ from $\mathrm{N}$ would not be lawfully sufficient for Y. To use an example deployed by J.L. Mackie, ${ }^{37}$ an electrical short circuit in the basement of a house is a NESS for the resulting fire that destroyed the house, because there was a set of factors $\mathrm{N}$ that includes the fact that the shortcircuit occurred where those factors together constitute a lawfully sufficient condition for the fire's occurrence. Those factors without the short circuit

33. See supra text accompanying note 20 (defining NESS).

34. See Wright, Causation, supra note 1, at 1740, 1789

35. Conversation with Richard Wright in Iowa City, Iowa (Nov. 6, 2000).

36. In most articulations of his view, it seems to us that Wright does not distinguish lawful from causal sufficiency. There are occasional passages in which he might seem to be invoking a concept of causal, as opposed to lawful, sufficiency. See Wright, Bramble Bush, supra note 1, at 1029-34. In these passages, however, Wright is responding to Mackie, who deploys the language of causal regularities and causal statements. See J.L. MACKIE, The CEMENT OF THE Universe: A Study OF CAUSATION 77 (1974). Furthermore, he has suggested in conversation with the authors that he had in mind causal as opposed to lawful sufficiency as the critical concept of sufficiency defining the concept of a NESS. Conversation with Richard Wright in Iowa City, Iowa (Nov. 4, 2000). As we shall see, Wright's account faces insuperable problems handling cases of preemption unless he invokes a distinction between lawful and causal sufficiency. But by appealing to an unanalyzed notion of causal sufficiency, we shall argue, his view risks vicious circularity.

37. See Mackie, supra note 25, at 33-35. 
would not be lawfully sufficient for the fire. The short circuit was, trivially, a logically necessary condition for $\mathrm{N}$ to occur because $\mathrm{N}$ is simply a complex state of affairs that includes the short circuit as one of its constituents.

If we understand the concept of a NESS in the way suggested above, then the concept shares a formal problem with Mackie's definition of an INUS condition. At least the formal problem exists if we allow that there can be complex states of affairs that share the structure of truth-functionally complex propositions. Consider some state of affairs that is lawfully sufficient for the fire in my basement. Call it N. Now, the fact that I am wearing a blue shirt, B, is not a NESS of the fire by virtue of its being a constituent of this state of affairs. But consider the complex state of affairs that is (not-B or N). (Not-B or N) is not by itself lawfully sufficient for the fire; its obtaining does not require the occurrence of $\mathrm{N}$. But if we add to (not-B or $\mathrm{N}$ ) the fact that $\mathrm{B}$ has occurred, it follows that $\mathrm{N}$ has occurred. Thus the complex state of affairs ( $\mathrm{B}$ and (not-B or $\mathrm{N})$ ) is lawfully sufficient for the fire, and B is a nonredundant part of that lawfully sufficient condition. The blue shirt has implausibly entered the picture as a NESS of the fire. In Mackie's terminology the blue shirt has become a condition that is insufficient for the fire but a necessary part of a complex condition that was unnecessary but sufficient for the fire. Clearly, something has gone wrong.

If there really is a problem here, the solution is to be more specific about the sense in which a NESS must constitute a nonredundant part of a lawfully sufficient condition. Let us say that $\mathrm{X}$ is a nonredundant part of a lawfully sufficient condition for $\mathrm{Y}$ when $\mathrm{N}$ is a complex state of affairs that contains as a constituent $\mathrm{X}$, the other conditions that constitute $\mathrm{N}$ are not by themselves lawfully sufficient for $\mathrm{Y}$, and they do not contain as truth-functional ${ }^{38}$ constituent parts any of which by themselves are lawfully sufficient for $\mathrm{Y}$. That is, $\mathrm{Y}$ contains $\mathrm{Z}$ as a part when $Y$ is identical with a complex state of affairs that contains $Z$ as a logical constituent, for example $\mathrm{Y}$ is identical with ( $\mathrm{Z}$ or $\mathrm{K})$.

IV

\section{THE NESS TEST AND OVERDETERMINATION}

Wright argues that in certain conditions, the NESS test for a causally relevant factor is superior to the alternative "but for" test developed in traditional case law." Under the "but for" test, $\mathrm{X}$ is a causally relevant factor for the occurrence of $\mathrm{Y}$ when $\mathrm{Y}$ would not have occurred but for the occurrence of $\mathrm{X}$. The "but for" test seems to work well with garden-variety examples of causa-

38. A proposition is truth-functionally complex when it is composed of other propositions joined by connectives (words like "and," "or," "if ... then ...") such that the truth or falsehood of the complex proposition depends solely on the truth or falsehood of the constituent parts. The meaning of the connectives is exhausted by the way in which the truth or falsehood of the parts contributes to the truth or falshood of the whole. For example, whether it is true or false that either Washington was a President of the United States or Gore was a President of the United States depends solely on the truth or falsehood of the two propositions that are joined by the word "or."

39. See Smith v. Philadelphia Transp. Co., 195 A.2d 168, 170 (Penn. 1963); see also Wright, Causation, supra note 1 , at 1791-1803. 
tion. The short circuit was a causally relevant factor with respect to the occurrence of the fire because the fire would not have occurred but for the occurrence of the short circuit. The "but for" test, however, seems to fail in cases of overdetermination. To use a classic case, suppose that $\mathrm{S}$ shoots Jones and is, therefore, a pretty good candidate for being the cause of Jones's death. ${ }^{40}$ It turns out, however, that someone else had poisoned the tea Jones finished drinking and the poison has no antidote. Let us further suppose that the poison had its fatal effect at precisely the same time as the bullet. Jones would have died even if he had not been shot. It is not true that he would have lived but for the gunshot. But, intuitively, we want the gunshot to be the cause (or at least a causally relevant factor) of Jones's death. ${ }^{41}$

The proponent of the "but for" test has a possible response that deserves exploration. While both the wound from the bullet and the poison ended Jones's life, Jones's death would have been different in a number of respects had he died from either one alone rather than both together. Since Jones was shot as well as poisoned, he lost blood as he died. One could therefore argue that the wound was still a cause of Jones's death, for he would not have died in that way but for the wound. This response is problematic because of the way in which we have defined a NESS. We have argued that if we allow that facts are sufficient conditions for other facts at all, it is in a derivative sense. A fact $\mathrm{X}$ is lawfully sufficient for a fact $\mathrm{Y}$ when the proposition made true by $\mathrm{X}$ is lawfully sufficient for the proposition made true by Y. Now the world contains a plethora of facts. There is the fact that Jones died; the fact that Jones died painfully; the fact that Jones died and bled a great deal while he died; the fact that Jones died in a white house; the fact that Jones died in a white house surrounded by a picket fence; and so on. If the relata of causal connections are something like facts - the kind of thing that shares the structure of a proposition-then we can ask what the cause of Jones's death was where the fact that needs causal explanation is that generic fact (the fact that makes true the proposition that Jones died). It is just not true to say that Jones would not have died but for the wound. He would have died even if he would not have died in that way. So, given the "but for" test, my firing the gun would still not be a cause of $S$ 's death (even if it would be a cause of $S$ 's dying in that way).

One could, of course, argue that what the law needs is the concept of a causally relevant factor in the production of some maximally specified effect. But that seems to make the concept of a causally relevant factor far too broad to be useful. The pedestrian walking near Jones when I fired the gun exerted at least some gravitational influence on the bullet and, as a result, Jones did not die in precisely the way he would have died had the pedestrian not been there. But do

40. See Wright, Causation, supra note 1, at 1795.

41. See id. 
we really want to clutter our class of causally relevant factors with such clearly irrelevant details as the people in the vicinity of Jones? $?^{42}$

The NESS test seems to fare better in cases of overdetermination than the "but for" test. Clearly, the bullet was a nonredundant part of a set of conditions that is lawfully sufficient for Jones's death, and had such a role even if it is true that Jones would have died even had the bullet not been fired.

A. Does the NESS Test Presuppose Determinism: Is Being a NESS a Logically Necessary Condition for Being a Causally Relevant Factor?

Given the way in which we define lawful sufficiency, nothing is ever lawfully sufficient for anything in a radically indeterministic universe. For our purposes, we shall say that a universe is deterministic when each state or "time slice" of the universe is lawfully sufficient for the next and all subsequent states of the universe; an indeterministic universe is one that is not deterministic. A radically indeterministic universe is one in which no state is ever lawfully sufficient for any subsequent state. The NESS test presupposes determinism. Unless there is some universal law of the form "All $F$ s are $G$ s," being $F$ cannot be lawfully sufficient for being $G$. Yet it is far from clear that our concept of causal connection precludes the possibility of causes in an indeterministic world. ${ }^{43}$ If Wright's analysis of causally relevant conditions is correct, then to establish that some $\mathrm{X}$ is a causally relevant condition for the occurrence of some $\mathrm{Y}$, we would need to establish that there is some "covering law" that relates some complex condition (of which $\mathrm{X}$ is a part) to the occurrence of $\mathrm{Y}$. But surely my conclusion that your plunging the knife through Jones's heart was a causally relevant factor in his death does not await my conviction that these sorts of events are part of a deterministic universe. To take a somewhat far-fetched example, we might even consider a situation in which we have reason to believe that the phenomena in question are indeterministic. Jones plants a bomb in your home. It is an odd sort of bomb though, activated by the decay of a radioactive element that has a half-life of a thousand years. We will take quantum physics seriously and suppose that the decay of such elements is genuinely probabilistictwo elements exactly alike may be such that one decays after a minute, the other after two thousand years. This is not your lucky day. The element decays after five minutes and the bomb destroys your property and seriously injures you. You would expect a successful tort action against Jones and would not be happy if the judge rules that you lose because Jones's planting of the bomb in your house was not a NESS of your house being destroyed. It was not a NESS because, by hypothesis, the planting of the bomb was not a nonredundant part of a lawfully sufficient condition for your house being destroyed. Given the na-

42. David Lewis considers and rejects this revision of the "but for" analysis of causation for similar reasons. See David Lewis, Causation as Influence, 97 J. PHIL. 182 (2000).

43. For a more extensive discussion of causation without determinism, see G.E.M. Anscombe, Causality and Determination, in CAUSATION, supra note 25, at 88; and Wesley Salmon, Probabilistic Causation, in CAUSATION, supra note 25, at 137-53. 
ture of radioactive decay, it was not even probable, relative to any antecedent conditions, that your house would be destroyed (in your lifetime). In this case, the "but for" test seems to get things right. Even if my planting the bomb is not a NESS of the explosion, the explosion would not have occurred but for the fact that I made and planted the bomb.

One might suppose that the solution is to define a causally relevant factor as a condition that satisfies either the NESS test or the "but for" test. Unfortunately, this would be the wrong approach. While the "but for" test does seem to work better than the NESS test in the example of "indeterministic" causation, we encounter difficulties again when we combine a hypothetical situation in which there is indeterminism with a situation in which there is overdetermination. So suppose that I have planted my "randomly activated" bomb in your house and that it explodes five minutes afterward. You are not very popular, however, and another neighbor had, as it turns out, planted a "Newtonian fully deterministic bomb" that would have detonated ten minutes later had the first bomb not exploded. The planting of the first bomb is now neither a NESS of the destruction of your home, nor is it a factor that satisfies the "but for" test: It is not true that your home would not have been destroyed but for the planting of the first bomb. But it would be absurd to suppose that the planting of the first bomb was not a causally relevant factor in the destruction of the home.

\section{B. The Proliferation of NESSs}

There is another concern that one might have with the NESS test for something being a causally relevant factor. The concern can best be expressed as one about the utility of the concept. One might argue that we want the concept of a causally relevant factor to be one that results in a "manageable" number of causally relevant factors. If we give a jury instruction to pay attention only to causes that satisfy the NESS test, we would not want there to be an indefinite number of NESSs. Yet we probably cannot get that result. The problem is that, to get a set of conditions that is genuinely lawfully sufficient for some outcome, the set must contain indefinitely many conditions. Suppose that a switchman fails to pull the switch that would have prevented the collision of trains. Let us further suppose that the failure to pull the switch was a part of some enormously complex set of conditions that was sufficient for the collision. What other conditions would be a part of that set? There are the obvious: that the trains were on the tracks traveling at specific speeds; that the engineers on the trains did not know about the failure to pull the switch; that the engineers did not have the capacity to brake in time. But a bit of reflection tells us that there are indefinitely many other conditions the absence of which must be included before we have identified factors that are lawfully sufficient for the collision. Had you been carefully monitoring the switchman, the accident would not have occurred. Had your brother been carefully monitoring the switchman, the accident would not have occurred. Had Bill Gates been carefully monitoring the switchman, the accident would not have occurred. Had someone developed 
a safety device that told engineers when their trains were on a collision course, the accident would not have occurred. It is only the switchman's failure in the absence of all these factors-and indefinitely many more- that is lawfully sufficient for the accident. And that makes the absence of each of these other factors just as much a NESS of the accident as the brakeman's failure to pull the switch.

But is there really a problem here? In a sense, it depends on how much work we expected the nonnormative component of causal judgments to do in the context of law. If we expected the nonnormative causal conditions that must be met by an action for it to be tortious to help narrow down significantly the class of causally relevant factors that we could, in principle, consider in holding people legally responsible for their actions (and inactions), we might be disappointed by the fact that our nonnormative causal considerations still leave us with a plethora of actions (and inactions) to consider. But the appropriate reaction might well be that it was foolish at the outset to expect nonnormative factual causal considerations to do all that much work in this respect. It should have been obvious at the outset that the concept of proximate cause-a concept that is almost certainly laden with normative concepts-is what really does the work in significantly narrowing down the class of causally relevant factors that we want seriously to consider in a given context when it comes to determinations of law. What Wright should, and does, say is that it is still theoretically important to recognize that there is a nonnormative component to questions of what causes what, even if that nonnormative component must be heavily supplemented with implicit or explicit normative judgments when we make the transition from the judgment that S's action was causally relevant to the judgment that S's action was a proximate cause. ${ }^{44}$ Additionally, as Wright points out, causal conditions are narrowed because we need only look at tortious causal conditions. ${ }^{45}$

Furthermore, one can nevertheless reasonably point out that it is not a trivial question of fact whether some action of a defendant was a NESS of some harm. What $\mathrm{S}$ did may be one of indefinitely many actions and failures to act that are also NESSs of the same harm, but there are indefinitely many actions and failures to act that are not NESSs of the relevant harm. And if one can establish that one's action meets neither the NESS test nor the "but for" test of a causally relevant factor, one is still off the hook when it comes to legal liability, because legal liability requires that one has caused damages. So long as one does not expect nonnormative causal considerations to play more of a role than they can in determinations of law, one has no reason to worry much about the proliferation of NESSs.

44. See Wright, Causation, supra note 1, at 1741-42

45. See id. at 1793, 1803-13. 


\section{NESSS AND PREEMPTION}

We have suggested that one must not be unrealistic about the role that a NESS test can play in resolving critical determinations of law. Wright may have attributed more power to the NESS test than he should have. Specifically, Wright seems to think that his NESS test for being a causally relevant factor has the virtue of eliminating as causally relevant factors "potential causes" that have been preempted by actual causes. Consider an example closely related to, but importantly different from, one discussed earlier. In this example, a person dies of a gunshot wound after ingesting a poison, but before the poison has its effect. Wright claims that in these circumstances the person's poisoning was not a NESS of that person's death; ${ }^{46}$ therefore the poisoner would not have been liable in a tort action. He also considers the example of a bridge-delay case in which a ship was unable to make it to a port in timely fashion because of the collapse of a bridge that had blocked the river channel. As it turns out, there was another bridge further up the river that had also collapsed and would have prevented the ship from reaching its destination even had the first bridge remained intact. ${ }^{47}$ In the example, we may suppose that in the collapse of both bridges we can establish relevant parties who were negligent for the way in which the respective bridges were built. Wright claims that, while the collapse of the first bridge was a NESS of the ship's being prevented from getting to its destination, the collapse of the second bridge was not. ${ }^{48}$ Of the second bridge Wright says, "neither the second bridge nor the second injury was a necessary element of any set of actual antecedent conditions that was sufficient for the occurrence of the loss. The second bridge will cause a delay only if the boat reaches it, but the boat did not reach it." 49

Note that, in his discussion of the case, Wright slips into a less technical use of causal terminology. It is, one might suppose, intuitively plausible to argue that the collapse of the second bridge, a bridge that the ship could not even reach, was not a cause of the damages that the plaintiff suffered as a result of the ship not getting to its destination. But the relevant question before us here is whether the collapse of the second bridge (blocking the channel) was a NESS of the ship not getting to the destination. And all we need to establish to reach the conclusion that it was is that it was part of a complex set of conditions that was lawfully sufficient for the ship not making it to the relevant port; it was. The fact that the only available channel was blocked ahead of the relevant ship, together with a host of factors involving ships and what they lawfully can and cannot do, will, with the relevant laws of nature, entail that the ship did not get

46. See id. at 1795 .

47. See id. at 1796-97; see also HART \& HONORÉ, supra note 3, at 250-51.

48. See Wright, Causation, supra note 1, at 1797.

49. Id. 
to its destination in a timely fashion. That makes the collapse of the second bridge a NESS of the relevant damage, contrary to what Wright argues.

Wright seems to think that the only relevant laws from which one could deduce the ship's not reaching port from the premise that the second bridge has collapsed are laws that refer to the ship's reaching the second bridge. But clearly there are laws precluding various possibilities that make no reference to the specific location of any ship but which allow us to deduce that no ships below the bridge proceed past the bridge.

The problem is related to a point we made earlier in distinguishing lawfully necessary and sufficient conditions from causally necessary and sufficient conditions. ${ }^{50}$ There does not have to be a causal chain leading from $\mathrm{X}$ to $\mathrm{Y}$ for $\mathrm{X}$ to be lawfully sufficient for $\mathrm{Y}$. And, of course, for the same reason, there does not have to be a causal chain leading from $\mathrm{N}$ to $\mathrm{Y}$ for $\mathrm{N}$ to be a nonredundant part of a lawfully sufficient condition $\mathrm{X}$ for $\mathrm{Y}$. X can be a lawfully sufficient condition for $Y$, even if $X$ occurred thousands of years before $Y$ and even if $X$ occurs thousands of years after Y. The barometer's falling can be a NESS of the subsequent storm without it being a causally relevant factor for the occurrence of the storm. Wright seems to want to distinguish the collapse of the second bridge from the collapse of the first by arguing that the second bridge is not a part of some actual conditions that were lawfully sufficient for the ship failing to reach its destination. But this just does not seem right. It is an actual fact that the second bridge collapsed, and it is an actual fact that the ship in question was below the bridge. These facts, together with other largely negative facts concerning the absence of alternative routes, are lawfully sufficient for the ship not getting to its port. And that makes the collapse of the second bridge a NESS of the ship not getting to its port.

If there is a solution available to Wright here, it probably lies in the direction of a deeper excursion into the metaphysics of causation. Earlier we drew a distinction between causally necessary and sufficient conditions and lawfully necessary and sufficient conditions. ${ }^{51}$ We did not explain the distinction other than to illustrate it with examples. Once we recognize, however, that one can have conditions that are lawfully sufficient for $Y$ that are nevertheless not part of a causal chain leading to $\mathrm{Y}$, we should also recognize that, in our quest for an analysis of a causally relevant factor, we need to make the distinction between lawful and causal sufficiency. To be sure, our resulting account of causally relevant factors will depend upon an understanding of an unanalyzed notion of causal sufficiency (or total cause). Still, we can try to offer an illuminating concept of causally relevant factors, assuming the concept of causal sufficiency.

For example, as we noted earlier, when the barometer falls rapidly, this is lawfully related, or related in a law-like manner, to a high probability that it will rain. It hardly follows that the barometer's falling causes it to rain. Similarly, we noted that when the sun is at a forty-five degree angle, and the shadow is

50. See supra text accompanying notes 32-33.

51. See supra text accompanying notes 31-32. 
five feet tall, law-like connections entail that the flagpole is ten feet tall. But it would surely be a mistake to claim that the shadow causes the flagpole to be ten feet tall. If anything, the direction of causation is from the flagpole's height to the length of the shadow. Similarly, Wright might be able to argue that, even though the second bridge is lawfully sufficient or has law-like sufficiency for delaying the plaintiff, it is not causally sufficient to delay the plaintiff. Thus, Wright might have more success handling cases of preemption and similar difficulties if he were willing to rely simply on an understanding of causal sufficiency rather than lawful sufficiency to explain his concept of a NESS. Might is the operative word however. We must recall that Wright's project is to analyze the meaning of the word or, alternatively, the concept of causation. ${ }^{52}$ If he deploys the concept of a causal law in defining causation, surely his critics will charge him with a vicious form of circularity-his NESS test for causation is nearly tantamount to defining causation as causation.

Professor Wright is caught between a rock and a hard place. To avoid the charge that he cannot handle certain cases of causal preemption, he must come up with a way to distinguish lawful (or law-like) sufficiency from causal sufficiency without relying on the concept of causation, a task that has eluded all philosophers to date.

\section{VI}

\section{CONCLUSION}

Judgments about causal connection play a critical role in determinations of law. It is tempting for a legal theorist to suppose that we should be able to supply judges and juries with an adequate and precise analysis of causal connection. This project, however, is probably doomed from the start. Philosophers have labored long and hard on the question of how to analyze causation, with a striking lack of success. ${ }^{53}$ Still, even if one must presuppose a fundamental understanding of lawful sufficiency, it is tempting to suppose that one could do something useful along the lines suggested by Wright. Wright does not pretend to offer a complete, philosophically adequate analysis of causation. In his own view, that would involve analyzing the concept of lawful sufficiency presupposed by the concept of a NESS, an analysis that must not presuppose an understanding of causation if it is to avoid circularity. But by presupposing an understanding of lawful sufficiency, Wright hoped to analyze what we might reasonably describe as causally relevant factors and analyze in a way that made clear that the concept in question is nonnormative. We have seen, however, that even Wright's modest task faces serious problems. The possibility that there can be causation in an indeterministic universe suggests that we should hesitate before we regard $\mathrm{X}$ being a NESS of $\mathrm{Y}$ as an analytically necessary

52. See Wright, Causation, supra note 1 , at 1740.

53. For a good survey of the problems various approaches face, see Ernest Sosa \& Michael Tooley, Introduction to CAUSATION, supra note 25 , at 1 . 
condition for $\mathrm{X}$ being a causally relevant factor in the occurrence of $\mathrm{Y}^{54} \mathrm{We}$ have also reached the conclusion that $\mathrm{X}$ being a NESS of $\mathrm{Y}$ is not an analytically sufficient condition for $\mathrm{X}$ being a causally relevant factor in the occurrence of $\mathrm{Y}^{55}$ We tentatively suggested that an analytically necessary condition for $\mathrm{X}$ being a causally relevant factor in the occurrence of $\mathrm{Y}$ might be the disjunction that either X is a NESS of Y or that Y would not have occurred but for the occurrence of $\mathrm{Y}$, but we discovered that the disjunctive proposal faces the same problem with cases of overdetermination that the "but for" test faced on its own. In our discussion of preemption, we saw that being a non-redundant part of a lawfully sufficient condition for $\mathrm{Y}$ is not enough to make something a causally relevant factor for $\mathrm{Y}$. The heart of the problem seemed to be that, minimally, we need a distinction within the class of lawfully sufficient conditions between those that are causally sufficient and those that are not. If we invoke such a distinction, we are not only making our analysis of causally relevant factors dependent on an understanding of the concept of law, we are making it depend on the concept of causal law. Revising the analysis of a NESS to take into account such a distinction does not render the analysis without importance. As long as one allows that one is only trying to carve out the nonnormative factual components of causal judgments, an account of a causally relevant factor that relies on the concept of causal sufficiency is still potentially valuable.

Are there other conclusions one might draw? We might wonder if there is not a more robust concept of causation, or at least a robust concept of causally relevant factors, that we simply are not reaching, either through the concept of a NESS or through the "but for" test of causation. When we understood the sufficiency in the concept of a NESS as lawfully sufficient, why did it turn out that some NESSs are not causally relevant factors? The NESS test proposed by Wright seemed to presuppose a highly controversial generality theory of causation. The generality theory of causation assumes that the concept of cause depends on the concept of lawful connection. The generality theorist argues that if we can define causal connection, it is only through an independent understanding of lawful connection. But the generality theory has come under considerable attack as a philosophical position concerning the metaphysics of causation. $^{56}$ As Wright himself implicitly admits in his discussion of preemption, there are other conditions crucial to $\mathrm{X}$ being a causally relevant factor in the occurrence of Y. Perhaps for X to be a cause of $\mathrm{Y}, \mathrm{X}$ must be part of a causal chain running through time where each link in the causal chain is just prior to the next link in the causal chain. As Hume initially suggested (and as many others have presupposed), it may also be essential to causal connection that

54. See supra Part IV.A.

55. See supra text accompanying notes 45-52.

56. For a sampling of such views, see Donald Davidson, Causal Relations, in CAUSATION, supra note 25, at 75-87; C.J. Ducasse, On the Nature and Observability of the Causal Relation, in CAUSATION, supra note 25, at 125-36; Michael Scriven, Defects of the Necessary Condition Analysis of Causation, in CAUSATION, supra note 25, at 56-59; Michael Tooley, Reduction versus Realism, in CAUSATION, supra note 25 , at $172-92$. 
each item in the causal chain be spatially contiguous with its immediate successor. ${ }^{57}$ Of course, we cannot put the relevant points the way we just did without rendering our analysis of a causally relevant factor hopelessly circular. But it is far from clear that one can restate any of the above common sense ideas into the language of NESSs, or, for that matter, into the language of the counterfactual "but for" conditions for causal connection. ${ }^{58}$

The generality theorist can go a long way by simply invoking an unanalyzed distinction between causal laws and other sorts of laws, but the critic of generality theories will urge us to consider whether it is not more plausible to construe the concept of a causal law as one that presupposes some more basic and primitive understanding of causation as a relation holding between particular events. More specifically, the critic will urge us to understand causal laws as generalizations about kinds of events standing in causal relations. ${ }^{59}$ But if we define causal laws appealing to our understanding of causal relations, ${ }^{60}$ we obviously cannot gain insight into the nature of causal relations through an appeal to our understanding of causal laws.

Wright's NESS account of actual causation was intended to follow the spirit of a Humean regularity theory of causation. ${ }^{61}$ But the essence of a Humean account of causation is one in which we try to understand X's causing $Y$ in terms of "brute" regularities in nature that involve constant conjunctions between $\mathrm{X}$ like events and Y-like events. ${ }^{62}$ To succeed, such a regularity theory must avoid all invocations of the concept of cause in the identification of the relevant regularities that are supposed to constitute causal connection. As a good Humean, Wright may invoke the concept of lawful sufficiency provided that he is prepared to understand it in terms of mere regularities. If he appeals to causal sufficiency, he owes us an account of causal laws that does not require a more fundamental understanding of causation.

It would be nice if we could end this article with an illuminating noncircular account of the essence of causal connection, but we cannot. Philosophers have long recognized that there is an intimate connection among the concepts of causal connection, lawful connection, and the relation expressed by contingent counterfactual (subjunctive) conditionals—statements of the form: If Q were to occur, Q would occur, or if Q had not occurred, Q would not have occurred.

57. See HUME, supra note 8, at 75-77.

58. Every few years, David Lewis refines his counterfactual ("but for") analysis of causation to account for criticisms of it and counterexamples that have been urged against it. See, e.g., David Lewis, Causation, 70 J. PHIL. 556 (1973). The latest is David Lewis, Causation as Influence, 97 J. PHIL. 182 (2000).

59. This is the approach taken by Donald Davidson. See Davidson, supra note 56, at 75.

60. See HuME, supra note 8, at 87-89; see also DAVID HUME, AN INQUIRY CONCERNING HUMAN UNDERSTANDING 75-79 (L.A. Selby-Bigge ed., Oxford University Press 1975) (1777) ("[W]e may define a cause to be an object, followed by another, and where all the objects similar to the first are followed by objects similar to the second." (italics in original)).

61. Wright, Causation, supra note 1, at 1774 (stating that his theory is an elaboration of "a causal test that incorporates the Humean philosophic account of the meaning of causation, as modified by John Stuart Mill."); see also id. at 1789-90.

62. See HuME, supra note 8, at 168-70. 
The trick has been to get a philosophically adequate account of one of these concepts that does not presuppose an understanding of either of the other two so that one could then employ it in saying something illuminating about the remaining two. It has not been an easy trick to accomplish. An increasing number of philosophers seem to be willing to take the concept of causal connection as a primitive (unanalyzable) concept-one of the conceptual atoms out of which we build more complex concepts or ideas. But one does not need to be overly cynical to wonder whether this embrace of an unanalyzable relation of causal connection is not born out of sheer frustration with the inability to say something interesting yet true about what constitutes the essence of causation. In any event, if the law is waiting for philosophers to offer something better than a prephilosophical grasp of what is involved in one thing causing another, the law had better be very patient indeed. 